\title{
Research on Information Economy Promoting Transformation and Upgrading of China's Industry in the View of Ecological Civilization
}

\author{
Yan Xuhui \\ School of Public Administration, South China Normal University, Guangzhou, China
}

\section{Email address:}

yanxuhui@m.scnu.edu.cn

\section{To cite this article:}

Yan Xuhui. Research on Information Economy Promoting Transformation and Upgrading of China's Industry in the view of Ecological Civilization. Science Innovation. Vol. 5, No. 4, 2017, pp. 202-210. doi: 10.11648/j.si.20170504.12

Received: March 13, 2017; Accepted: April 7, 2017; Published: May 4, 2017

\begin{abstract}
The industrial economy in past 100 years had caused serious damage to earth ecosystem. Nowadays China government is launching the reform of ecological civilization which emphasizes that human and nature are regarded as a community of destiny, and it encourages using the new technologies and new methods to achieve common prosperity and common development of human and nature. At present, the booming information economy takes information as the factor of production. It promotes the effective matching of supply and demand in market transactions. The deep integration of modern information technology and traditional industries will promote industrial upgrading and drive regional economic growth. The information economy will promote the human society to reduce consumption of natural material and energy, and it will reduce the damage to the ecological environment. Hence, it will achieve the harmonious development for human and nature.
\end{abstract}

Keywords: Ecological Civilization, Information Economy, Industrial Transformation and Upgrading, Sustainable Development

\section{生态文明视角下信息经济推动中国产业转型升级的研究}

\section{间旭晖}

公共管理学院, 华南师范大学, 广州, 中国

\section{邮箱}

yanxuhui@m. scnu. edu. cn

摘要：人类社会近一百多年来的工业经济已给地球生态系统造成严重的伤害。当前中国政府推行的生态文明体制改革 强调把人与自然看作是一个命运共同体，努力运用新技术、新方法来实现人与自然的共同繁荣、共同发展。信息经济 以信息为生产要素, 它使现代信息技术与传统产业的深度融合, 促进了市场经济中供给与需求的有效对接。信息经济降 低人类对物质和能源的消耗，减少对生态环境的破坏，它最大程度地实现人与自然的和谐发展。

关键词：生态文明，信息经济，产业转型升级，可持续发展 


\section{1. 引言}

经济增长和人类社会可持续发展一直是国际社会共 同关注的话题。20世纪60年代末, 30位来自欧美国家的企 业家和的科学家聚集在意大利罗马猞猁学院, 他们对那些 影响人类生存与发展的、涉及到全球经济、生态、政治、 社会的复杂性问题进行了前瞻性的研讨。他们这种自发的 研究活动进而促成了国际著名智库组织 “罗马俱乐部” 的 形成。1970年在罗马俱乐部委托之下, 美国麻省理工学院 的系统动力学小组启动了一项旨在探明地球生态系统与 经济增长之间关系的动力学研究。两年之后, 该项目小组 出版了《增长的极限》一书。该书向人们提出了一些令人 发人深省的问题: 当前人类社会所奉行的政策究竟是走向 一个可持续发展的未来, 还是走向一个崩溃的未来? 人类 社会应该怎么做才能保持经济增长与地球生态平衡的可 持续性? [1] 如今近半个世纪过去了, 我们发现在工业经 济快速发展之后, 人类社会的非理性繁荣已导致了自 2008 年以来的全球范围内的经济危机。与此同时, 传统经济增 长模式对地球生态环境的危害后果日益暴露出来。据国际 非营利组织 “全球生态足迹网络” 所提供的数据, 当前人 类的生态足迹已是地球生态承载力的 1.5 倍, 在中国地区, 这一比例甚至扩大到了 3.6倍。[2]许多迹象表明, 探讨和 反思现代经济发展与生态环保之间的协同关系既是时代 发展的呼唤, 同时也是一项关乎人类社会生存与发展的重 要课题, 本文将以此作为出发点, 从生态文明和系统整体 论的视角来探讨信息经济对中国经济增长和产业转型升 级带来的推动作用。

\section{2. 地球面临的生态危机}

上世纪70年代, 美国麻省理工学院系统动力学研究小 组采用了系统动力学和计算机建模技术对世界经济增长
的原因及其后果进行了系统分析, 他们的研究向世人呈现 了这样的一幅图景: 人类社会对经济增长的过度追求进而 导致了人口数量、资源消耗等活动呈现指数形式的变化。 然而, 与此同时地球所能提供的资源是有限的, 地球生态 对人类活动所产生的污染和排放的吸纳能力也是有限的, 随着人类生态足迹的不断扩大, 地球生态资源已出现了严 重的超载现象, 然而, 人们的觉醒和反应总是滞后的, 人 类社会现行的政策将可能导致使社会经济在未来几十年 之后出现大幅度衰退或崩溃。

上述观点的提出曾引发社会各界的关注与争议, 有人 认为这是一种危言等听或离经叛道的结论。但如今四十多 年过去了, 我们发现上述图景的某些预言正慢慢演变为一 种社会现实。例如, 地球表面的森林覆盖面积正从农业社 会之前的60-70亿公顷森林减少到目前大约 39 亿公顷, 其 中自然森林有近一半以上的消失是发生在 20 世纪 50 年代 以来的工业经济鼎盛时期。森林面积的大规模减少, 进一 步削弱了大自然对工业污染和排放的吸纳能力, 并导致大 气层中二氧化碳含量的增多, 这在一定程度上加剧了全球 温室效应。来自英格兰东安格利亚大学的 “全球气候研究 小组” 最近的研究结果显示, 地球温度自1860年以来已经 上升了大约 0.6 摄氏度, 其中在最近的 40 年里全球气温上 升趋势非常明显, 见图1。[3] 2016年美国国家海洋局和 大气管理局指出 2016 年 5 月气温已创出人类现代历史上新 高, 地球变暖所产生的极端天气将触发厄尔尼诺等自然灾 害的发生。[4]英国剑桥大学海洋物理学家彼得. 沃德汉姆 斯（2016）认为, 在全球变暖的作用下, 在2016年和2017 年的夏季, 北极地区的冰盖层将会大面积消融, 这将会导 致北半球气候出现异常, 同时还将给北极圈带来严重的生 态危机。

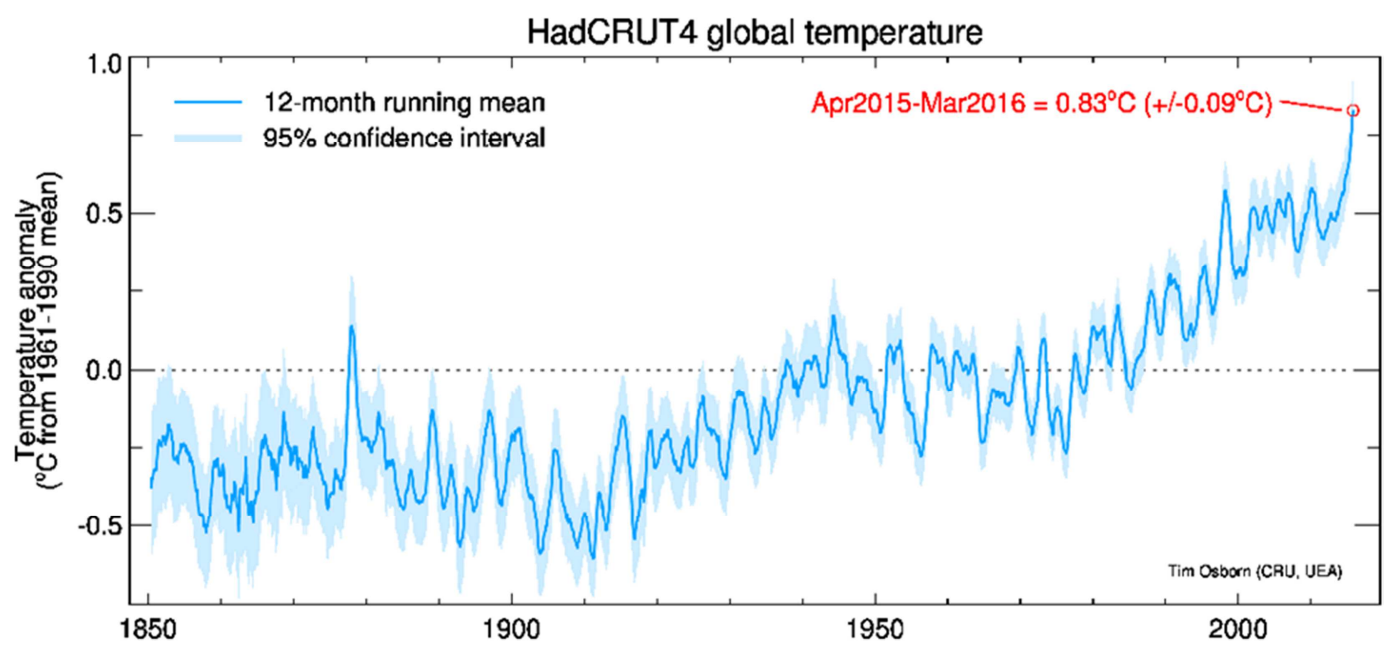

图1 1850年以来地球温度变化曲线图（摘自英格兰东安格利亚大学的 “全球气候研究小组”）。

当前国际环保组织常用 “生态足迹”（Ecological footprint) 和 “生态承载力 (Biocapacity)” 来对全球 的生态环境进行评估。生态足迹是指那些能够提供人类现 有生活方式所必需的土地面积以及用于吸纳人类使用矿
物能源排放的二氧化碳所需的土地面积。这些土地可细分 为谷物地、放牧地、林地、渔场以及建筑用地。生态承载 力表示地球生态圈能够产生和再生生命能力所需土地面 积。根据2016年国际非营利环保组织“全球生态足迹网络” 
(footprint network) 提供的数据, 目前全球有将近一 半以上的大陆面积出现生态承载力超负荷的状况, 其中亚 洲、中东、北非、北美等地区的生态足迹是当地生态承载 力的1.5倍。对此，世界自然基金会在其《2014年生存星 球报告》中已向世人发出了警告：“当前人类的对自然界 的需求在不断增长, 但这却是不可持续性的。人类砍伐树 的速度已超过树木生长的速度，人类的捕鱼速度超过其繁 殖的速度, 人类排放到大气中的二氧化碳已超出了森林和 海洋所能吸纳的能力。人类将需要 1.5 个地球才能产生足 够的自然资源以满足现有的活动需要。” [5]

\section{3. 中国面临的生态危机}

在地球生态环境日益恶化的同时, 中国所面临的生态 危机更加严峻。根据2016年国际非营利组织 “全球生态足 迹网络” 所提供的数据, 中国目前的生态足迹是生态承载 力的3.6倍, 处于严重生态超载状态。图2是2012年中国科 学院地理科学与资源研究所刘东等人对中国生态承载力 供需关系的研究结果。他们的研究结果显示, 在中国生态 赤字区域主要分布在中国中东部经济发达地区, 这些地区 虽然约占国土面积三分之一, 但却居住着中国 $80 \%$ 的人口。
其中, 京津冀、渤海湾、黄淮海平原、长江三角洲、珠江 三角洲、浙闽粤沿海等沿海经济发达地区的生态承载力已 处于严重超载状态。 [6]

与此同时, 近几年来受到地区工业经济直接或间接影 响, 中国部分地区气候面临雾䨪的侵扰, 根据中国气象局 发布的《2015中国气候公报》，2015年中国共出现11次大 范围、持续性的雾霾天气, 主要集中在1月和11-12月。其 中2015年12月19-25日, 华北中南部、黄淮大部、江淮东 部及陕西关中等地出现中到重度霾, 重度䨪面积达 19.1 万平方公里。华北中南部、黄淮大部出现大面积严重污染, 北京南部、河北中南部部分地区PM2.5峰值浓度均超过500 微克/立方米, 河北南部局地超过 1000 微克/立方米。可见, 雾䨪天气已给当地的经济发展和人民的生活带来极大侵 害。

上述数据表明, 现阶段中国的经济增长模式和产业结 构格局已经直接或间接地对当地的生态环境以及人民的 生活产生了不同程度的危害, 这需要我们进一步思考现阶 段经济增长模式和产业结构转型升级该如何与生态环境 保护相适应。

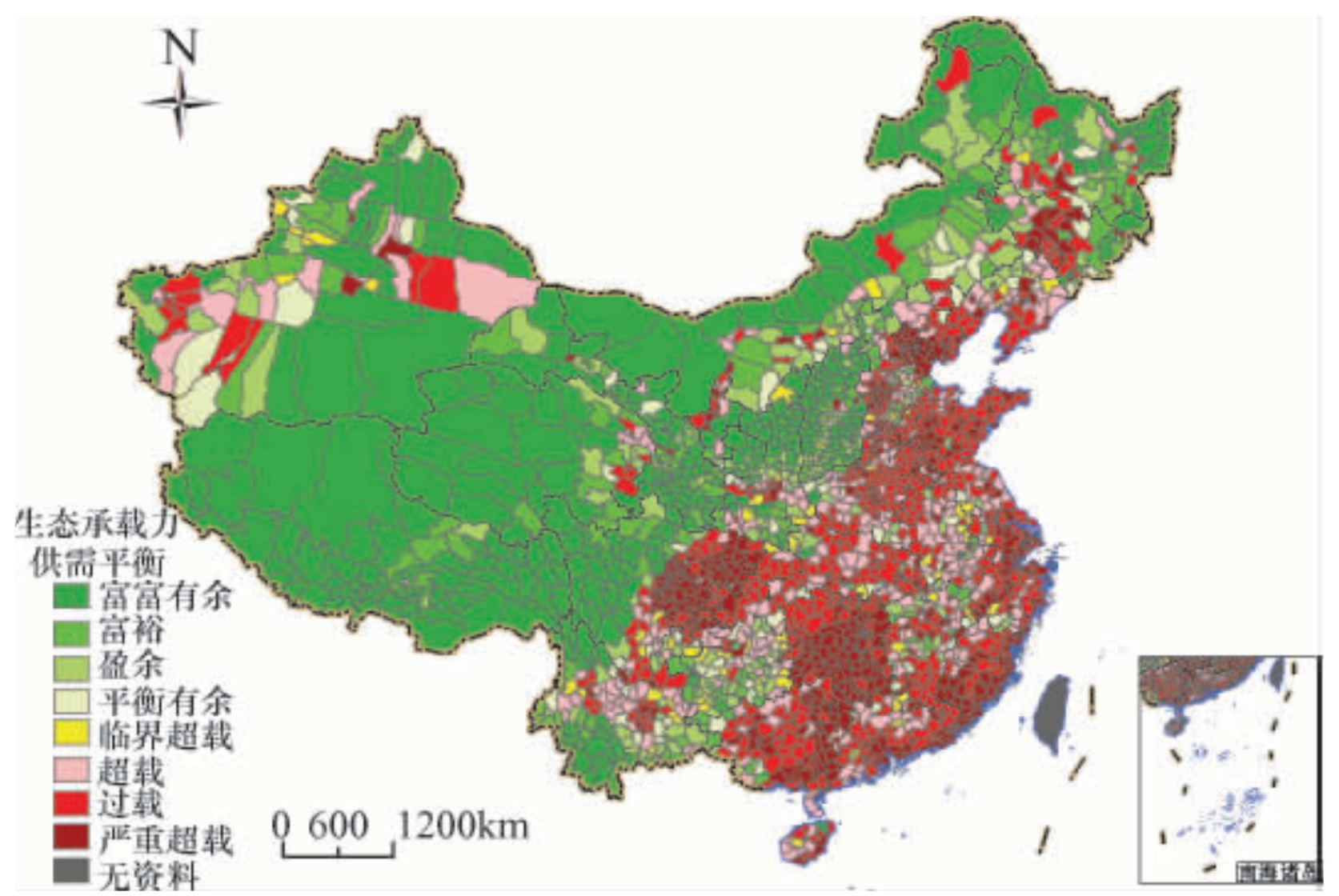

图2 中国生态承载力供需平衡空间格局。

\section{4. 经济增长模式与产业结构对生态的影响}

中国自1978年改革开放以来，国内生产总值GDP的年 增长率一直保持在 $4 \%$ 以上的快速发展状态。图 3 和图 4 显示, 在2000年到2014年期间, 中国GDP平均年增长率比世界GDP
平均年增长率高出约 7 个百分点, 比美国同期GDP平均年增 长率高出约 8 个百分点, 比德国同期GDP平均年增长率高出 约9个百分点, 2014年中国国内生产总值达到 10.48 万亿美 元, 世界排名第二, 仅次于美国。[7] 数据表明中国拉动 世界经济增长的火车头地位非常明显。 
1978-2014年中国GDP增长与世界GDP增长的对比图

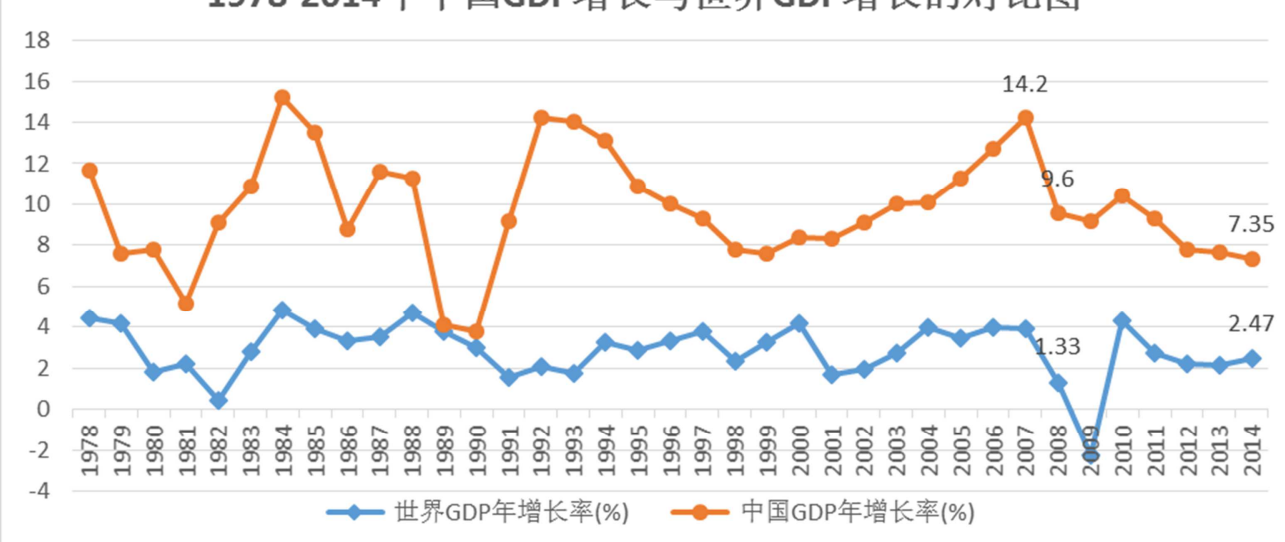

图3 1978-2014年中国GDP增长与世界GDP增长的对比。

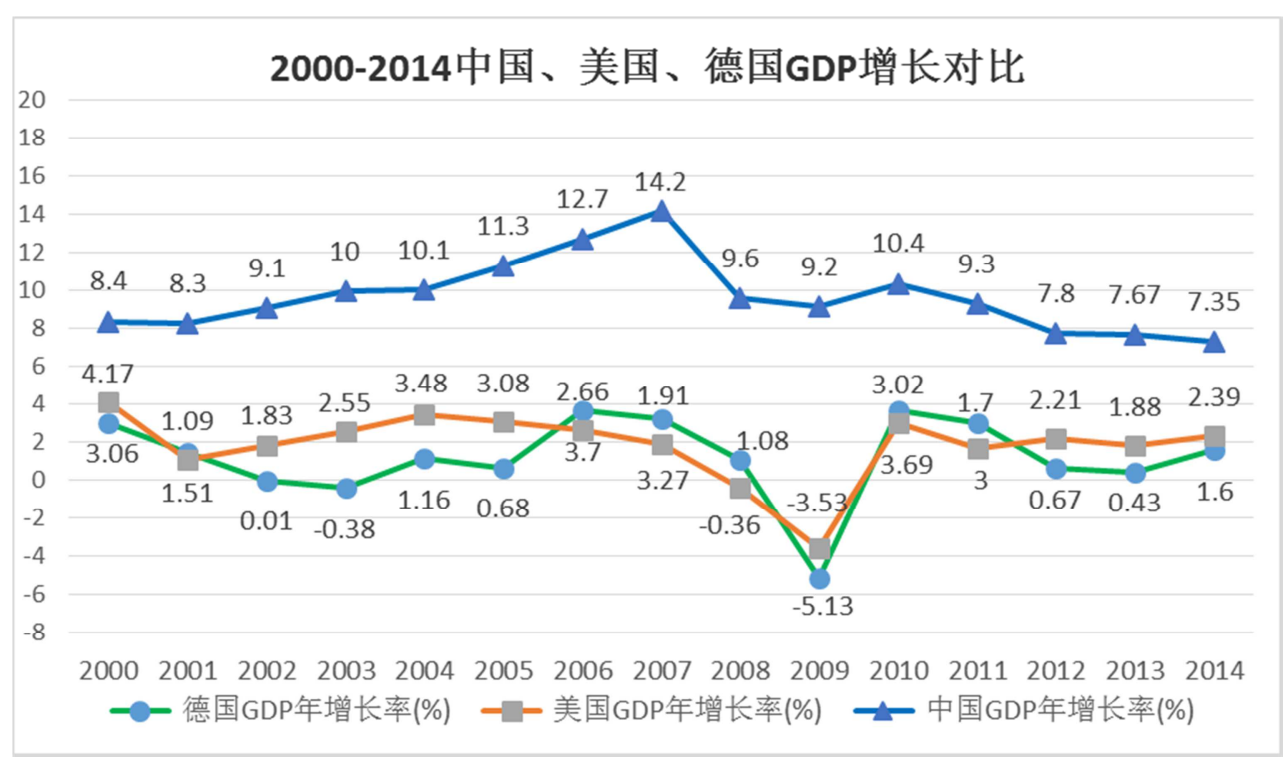

图4 2000-2014年中国、美国和德国GDP增长对比.

（\%） 1978-2014中国三次产业在国内生产总值中的占比趋势

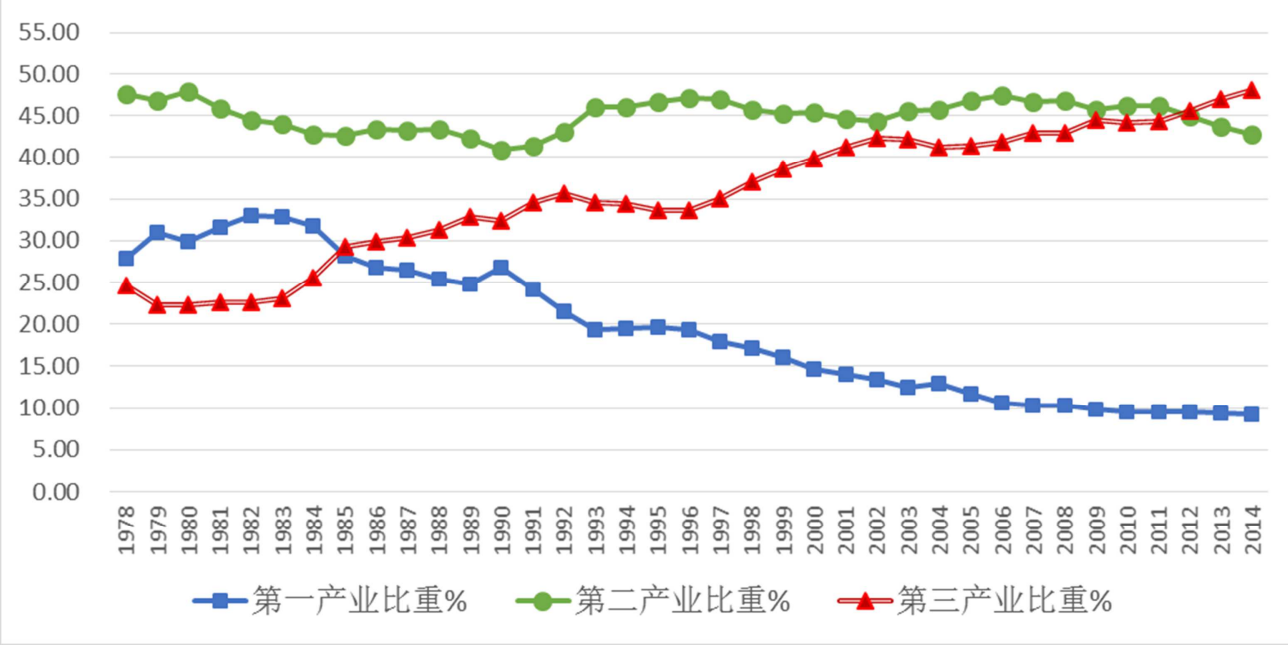

图5 1978-2014年中国三次产业在国内生产总值中的占比。 
中国经济的高速发展过程同时也是中国产业结构变 迁的过程。从三次产业结构演变的维度来看, 自1949年新 中国建立以来, 农业作为第一产业的主导地位已逐渐被第 二产业和第三产业所超越。1957年第二产业已开始超越第 一产业并成为国民经济中的主导产业, 其中重工业和轻工 业在整个经济中比重之和达到了 56. 7\%。[8] 1978 年以来, 随着十一届三中全会的召开, 中国改革开放的序幕正式拉 开，此后三次产业结构出现了进一步分化，见图5。从1978 年到2014年期间，中国的第一产业的比重从改革开放初期 的 30\%左右下降到10\%左右; 第二产业的比重一直稳定在 42\%-48\%的高位区间。在这段时期，中国工业制造业凭借 资源和成本的比较优势逐渐奠定了 “世界工厂”地位。与 此同时，改革开放激活了以金融业、房地产业、批发零售 业和交通运输业为代表的第三产业的快速发展。1985年第 三产业的占比开始超越了第一产业，2012年第三产业占比
开始超越了第二产业，2014年第三产业占GDP的比重已上 升到 $48 \%$ 左右, 其拉动经济增长的主导作用开始显现。

回顾中国经济三十多年的发展历程, 我们看到中国的 第二产业和第三产业的发展虽然起步较晚，但却用了不到 70 年的时间消化吸收了西方发达国家自 18世纪下半叶以 来的工业化经验成果, 这充分体现出中国社会主义制度的 优越性和改革开放带来的活力。但在另一方面, 我们也应 看到中国在产业结构布局、经济增长的质量和产业素质等 方面还与发达国家存在较大差距。例如, 在1998年到2012 年期间, 美国三次产业在非政府部门所创造GDP的比重当 中, 第一产业和第二产业在占GDP的比重将近 $20 \%$, 而以低 消耗、高附加值的服务业推动了第三产业在GDP的占比高 达 $70 \%$ 以上, 它是拉动美国经济增长和解决就业的主导力 量，见图6。[9] 其中信息服务业、金融业的发展是美国 经济长期增长的重要源泉。[10]

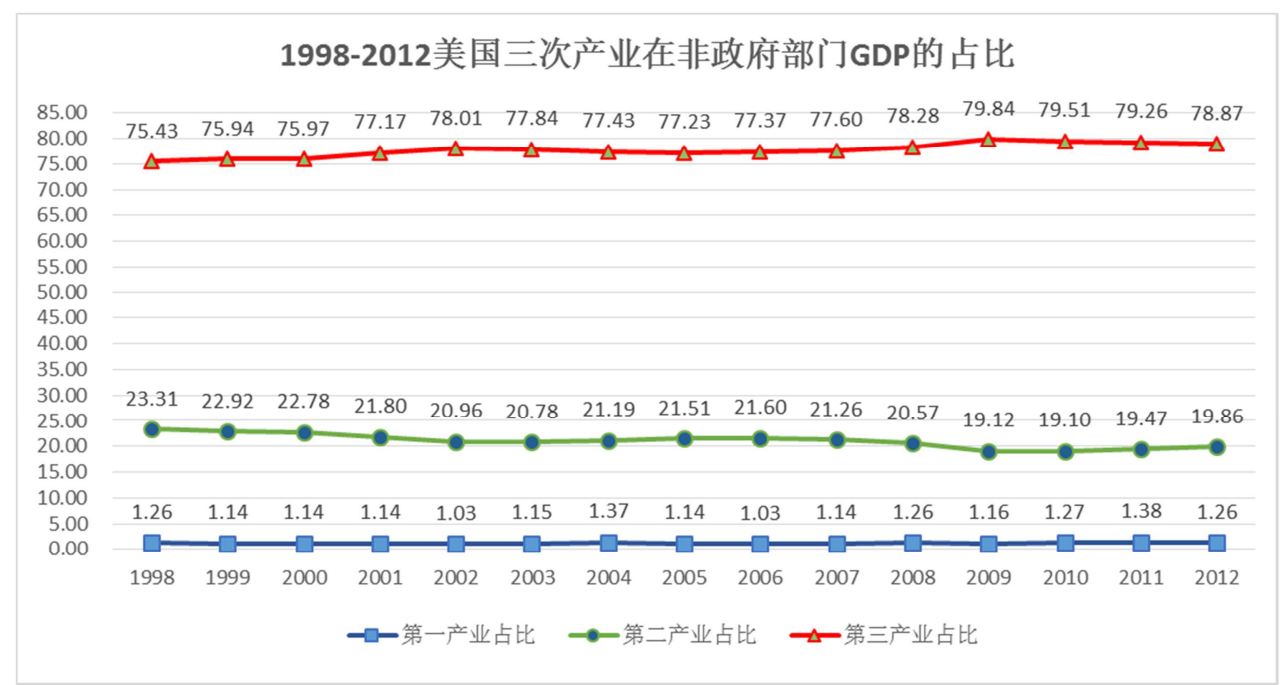

图6 1998-2014年美国三次产业在非政府部门GDP的占比(数据来源于美国商务部经济分析局网站http://www. bea. gov/industry/iedguide. htm\#gpo)。

在中国，尽管第三产业占GDP的比重这几年超越了第 二产业，但第二产业所占GDP的比重一直保持在 $40 \%$ 以上的 高位, 这意味着中国经济增长很大程度上还离不开第二产 业。值得关注的是, 第二产业高比重的背后的是长期以来 的高投入、高耗能、高污染和低附加值的粗放型发展模式。 然而, 这种粗放模式目前正遭受不同层面的挑战: 一是中 国粗放发展模式所依赖的资源和成本的比较优势正在丧 失, 尤其随着近 10 年房地产价格的快速攀升、人民币升值 和国内劳动力成本上升, 这种趋势很大程度挤压了国内工 业制造业的成本优势和生存空间; 二是全球经济自 2008 年世界金融危机之后已步入衰退期, 外部需求的下滑直接 导致国内工业制造业出现产能过剩的问题; 三是过往的粗 放型发展模式急剧扩大了人类生态足迹并加重了生态环 境的负担, 生态环境的恶化所产生负面效应（如雾霧、沙 尘）反过来正在逐步侵害到地区经济发展和人民生活。

总体来看，中国以往的依靠工业制造业、房地产和基 础建设拉动经济增长的模式大都是以消耗物质资源、增加 污染排放为代价的粗放型增长。从效果来看, 短期虽然能 够起到稳增长的效果, 但从长期来看, 这是一种透支生态
福祉的不可持续模式。从产业结构的发展状况来看, 在以 往依靠投资和扩大生产规模的经济增长模式中, 由技术和 效率等产业素质的提高所带来的增长效应并不显著, 有时 甚至出现规模增长, 素质下降的倒挂现象。[11] 由此可见, 在后工业时期, 中国的经济增长需要从社会可持续发展的 整体视角出发, 经济增长需要与生态环境相适应, 需要运 用新技术、新方法来提升产业的素质和经济增长的质量。

\section{5. 中国的生态文明体制改革}

上述对中国生态环境、中国经济增长和产业结构的现 状分析表明, 经济的增长与生态环境的保护和产业结构之 间存在相互作用、相互依赖的关系。如果我们把全人类的 生存发展看作是最高目的, 那么保护地球生态环境是实现 这一目的的先决条件。其中, 经济增长只是人类在追求生 存和发展的过程中的一种手段, 而产业结构和资源配置又 是实现经济增长的一个手段。显而易见, 手段是为目的服 务, 但如果我们因过分地追求手段而损害到了目的, 那么 这将本末倒置得不偿失。为此, 一个良好的产业结构和经 
济增长模式应该能够既满足经济增长的需要, 又可以使人 类的生态足迹控制在地球生态承载力的范围之内, 进而保 证人类社会和地球生态系统的可持续发展。同时,一个良 好的生态环境反过来可以为人类的生存、经济的增长提供 充足的物质保障。

人类该如何协调处理好生存发展、经济增长和生态环 保这三者之间的关系呢? 笔者认为, 这需要我们站在全人 类的角度, 把人类和人类所赖以生存的地球看作是一个命 运共同体, 自觉以生态文明 (Ecological Civilization) 的视角来认识和处理人、社会和自然之间的相互关系。这 种生态文明视角就是把全人类的生存发展和地球生态系 统的可持续发展看作是最高目的, 它强调人与自然都是地 球生态系统中不可或缺的重要组成, 人与自然之间不是统 治与被统治、征服与被征服的关系, 而是相互依存、和谐 共处、共同发展的关系。

关于这一点, 中国古代 “天人合一” 的思想已充分诠 释出来, 本文在此就不再赘述。值得关注的是, 中国在近 几年全面深化改革的道路相继做出了许多令世人瞩目的 创举, 其中推行生态文明体制改革就是一项重要举措。 2012年在中国十八大报告中明确地提出把发展生态文明 看作是 “追求全社会共同福祉, 建设资源节约型和环境友 好型社会、促进人类与自然和谐发展的必由之路”。2015 年9月中国政府正式颁布了《生态文明体制改革总体方案》, 它标志着中国正在引领人类社会向比农业文明、工业文明 更高层次的社会形态迈进。

\section{6. 信息经济带来的发展机遇}

从生态文明的视角来看, 人类社会该如何避免生态环 境的超负荷运作? 产业结构该如何调整? 新经济应采用 什么样的增长模式? 这些问题很早就引发国内外学者的 思考。美国学者丹尼斯. 梅多斯 (2003) 在《增长的极限》 一书中就曾指出: “人类社会要避免生态过冲, 就应努力 缩减对能源和物质的消耗, 生态足迹必须通过非物质化 (更少利用能源和物质来获得同样的产出) 、提高社会公 平程度 (把能源和物质的收益在富人和穷人之间重新分配) 以及改变现有的生活方式 (降低需求或者把消费转向那些 对物质环境带来更少负面影响的商品和服务) 来加以缩 减。” [12]梅多斯的观点是敏锐的，尤其她提到的以非物 质化的方式来降低人类在生产和生活中所消耗的物质和 能源以及由此带来的污染和排放, 这的确是一个非常有启 发性的建议。本文接下来就是要表达这样一种观点: 即基 于信息和信息技术的信息经济是一种以非物质方式来改 造人类生活和生产的有效手段, 它一方面能有效降低人类 对物质和能源的消耗以及由此带来的污染和排放; 另一方 面, 信息经济能够推动地区经济的实现绿色增长。

\section{1. 信息（数据）作为一种生产要素}

在人类认识世界和改造世界的进程中, 物质、能量和 信息这三个要素发挥了重要的作用。18世纪下半叶, 英国 工程师詹姆斯. 瓦特对蒸汽机技术的改良工作促进了工业 生产领域把热能转化为机械运动的应用, 进而推动人类社
会进入了采用机器来提高劳动生产效率的“蒸汽机时代”。 19世纪下半叶以来, 随着欧美科学家对电磁现象认识提高 和工程师们对电能获取、转化和传输的发明应用, 人类社 会开始进入了一个以电能来驱动机器的 “电气时代”。在 这一时期, 以电报、电话、电子计算机和大规模集成电路 为代表的电子信息技术产业进入了高速发展期, 这进而推 动了信息产业、信息经济的蓬勃发展。20世纪90年代以来, 围绕着计算机互联网技术和新能源技术的普及应用, 全球 发达国家和新兴发展中国家的正在经历着新一轮产业变 革。例如, 2012年美国通用电气公司提出了以发展智能网 络、智能决策为目标的 “工业互联网计划” ; 2013年德国 政府提出了发展智能工厂和智能生产的“工业4.0计划”; 2014年中国政府提出的把工业现代化和信息化深度融合 的 “中国制造2025计划”。美国学者杰里米. 里夫金把当 前基于互联网技术和新能源技术的产业变革浪潮称之为 “第三次工业革命”。[13]

在第三次工业革命浪潮中, 涌现出来的一个关键特征 就是信息 (数据) 作为新的生产要素被越来越多地应用到 生产和流通领域。信息和信息技术的普及应用成为了推动 了经济增长和社会转型的主导因素。[14] 在前两次工业 革命中, 推动经济增长的动力源主要是对物质和能量的发 明应用。然而, 在第三次工业革命中, 推动经济增长的动 力源则来自信息和信息技术的发明应用。其中信息呈现出 物质和能量所不具有的独特性: 从技术的角度来看, 所有 信息最终可还原为由 0 和 1 编码的数据文件, 它可通过有线 和无线的方式实现跨越时间和空间的存储、加工和传递等 活动, 它对生态环境产生的负面影响微乎其微。从经济的 角度来看, 信息在这些传递、分享的过程中没有像物质和 能量那样出现边际递减的现象, 相反, 信息在被加工、提 炼、分享和应用之后, 将会衍生出更多有价值的信息和知 识, 这就是信息所带来的边际递增效应。

在信息技术飞速发展的今天, 现代企业越来越多的产 品和服务不再以物质形式表现出来, 而是以数据、信息和 知识等非物质的形式出现在生产和流通领域。信息化的产 品和服务将以一种低成本、快捷和精准定位的方式满足人 们在物质层面和精神层面的需求。在国民经济结构当中, 这种以信息资源作为生产要素, 以信息通信技术作为基础 设施, 通过把信息通信技术与传统产业深度融合来驱动经 济增长的模式已成为一种新的经济形态-----信息经济。 在一些西方发达国家, 信息经济已成为了驱动地区经济增 长的主导力量。例如, 美国在1993年至1996年期间的国内 生产总值 (GDP) 的增长中, 住宅建筑业占 $14 \%$, 汽车生产占 $4 \%$, 而信息产业则占 $27 \%, 1996$ 年美国GDP增长的33\%是由 信息产业创造的。[15] 中国近几年的信息经济发展迅猛, 根据中国信息通信研究院发布的《2015中国信息经济研究 报告》, 2014年中国信息经济总量达到16.2万亿元, 占GDP 的比重 $26 \%$, 对GDP增长的贡献率高达 $58.35 \%$, 信息经济已 成为拉动经济增长的重要动力。[16] 对于这一现象, 美国 经济学家罗默早在1986年发表的《递增收益与长期增长》 论文中就敏锐指出, 知识是继劳动和资本之后的另一个重 要的生产要素, 知识溢出是推动经济增长的主要动力。 [17] 


\section{2. 互联网+带来的创新机遇}

在信息经济发展的近二十年中, 信息技术作为一种生 产力, 它从成本、效率和顾客体验等方面极大地改造了传 统企业的运作模式, 进而带动了整个产业链出现了转型升 级。其中, 互联网带来的影响是深远的和具有颠覆性的, 它作为一种普适的技术, 使人们获取信息和知识的方式更 加自由、平等和快捷, 它赋予了个人和企业更多的商业机 会与自由选择的能力。随着互联网技术的普及应用, 互联 网所具有的跨时空、跨主体的泛在性（时间的泛在、空间 的泛在和主体的泛在)特征, 使得信息资源的分布式配置、 虚拟组织跨时空的建立和企业虚拟价值链的构建成为了 水到渠成的事。互联网这些特点打破了传统实体经济发展 受时间和空间的约束, 它最大程度地实现了以技术为边界, 以跨时空的方式将生产要素、技术资源、市场需求在全球 范围内进行整合, 这形成了一个跨时间空间分布的互联网 经济体。

当前, 基于互联网的传统产业信息化不仅是把企业传 统线下业务搬到线上运作, 同时在线上运作过程中还将会 产生一些传统线下经济所没有的商业需求, 这些商业需求 将会给其他更多基于互联网的企业带来发展的商机，同时 也给劳动力市场带来更多的就业机会。在市场经济体制当 中, 互联网经济一个明显的优势在于它实现了供给与需求 自由平等地对接, 在对接当中实现了社会资源优化配置、 降低了交易成本、进而降低了人类的生态足迹。

\section{7. 信息化推动传统产业的转型升级}

信息化推动传统产业转型升级就是以信息资源作为 生产要素, 以信息通信技术作为基础设施, 通过把信息通 信技术与传统产业深度融合来驱动产业转型升级和实现
经济绿色增长。下面将以中国的网络预约出租车业务发展 为例探讨信息化对传统出租车客运服务的带来变革影响。 中国出租车客运业务是城市公共交通系统中满足民 众出行需求的一个重要补充力量。然而长期以来打车难问 题也一直是困扰城市居民出行的热点问题。然而, 近几年 随着互联网经济如火如茶的发展, 这种格局正在逐渐被打 破。2015年10月交通运输部发布的《关于深化改革进一步 推进出租汽车行业健康发展的指导意见》和《网络预约出 租汽车经营服务管理暂行办法》等文件推动了传统出租车 客运服务出现了转型升级的势头。

在中国, 传统出租车行业是一个受地方政府主管部门 授权经营的特许经营行业, 在这个近乎半垄断的行业中, 出租车客运服务质量很大程度与司机和乘客所掌握的信 息有关。图7描绘了传统出租车客运服务的服务流程图。 从这个图中, 我们可以清晰地看到传统巡游类出租车在提 供在城市出行服务过程中, 司机与乘客往往处于信息不对 称的状态。这在一定程度上抑制了出租车服务供给的有效 性, 降低了服务的质量。例如, 在出租车在服务过程中, 作为需求一方, 在绝大多数的出行情境中, 因受到时间、 地点、情境等因素的限制乘客是不具备充分选择出租车的 自由, 他们只能在特定的时空约束条件下按照供给方有限 的安排来进行选择。[18]在此条件下, 乘客由于无法事先 知晓附近出租车的分布情况, 他们只能选择站在路边靠眼 睛去观察和靠手去示意出租车。这种情形在上班高峰时段 往往会导致多人争抢一辆出租车的戏剧性一幕。有时即使 乘客幸运的拦到了出租车, 也许会因为目的地不合适或因 司机交接班等原因而无法成行, 类似这些因素无疑会增加 乘客出行等待的时间成本和精神成本。

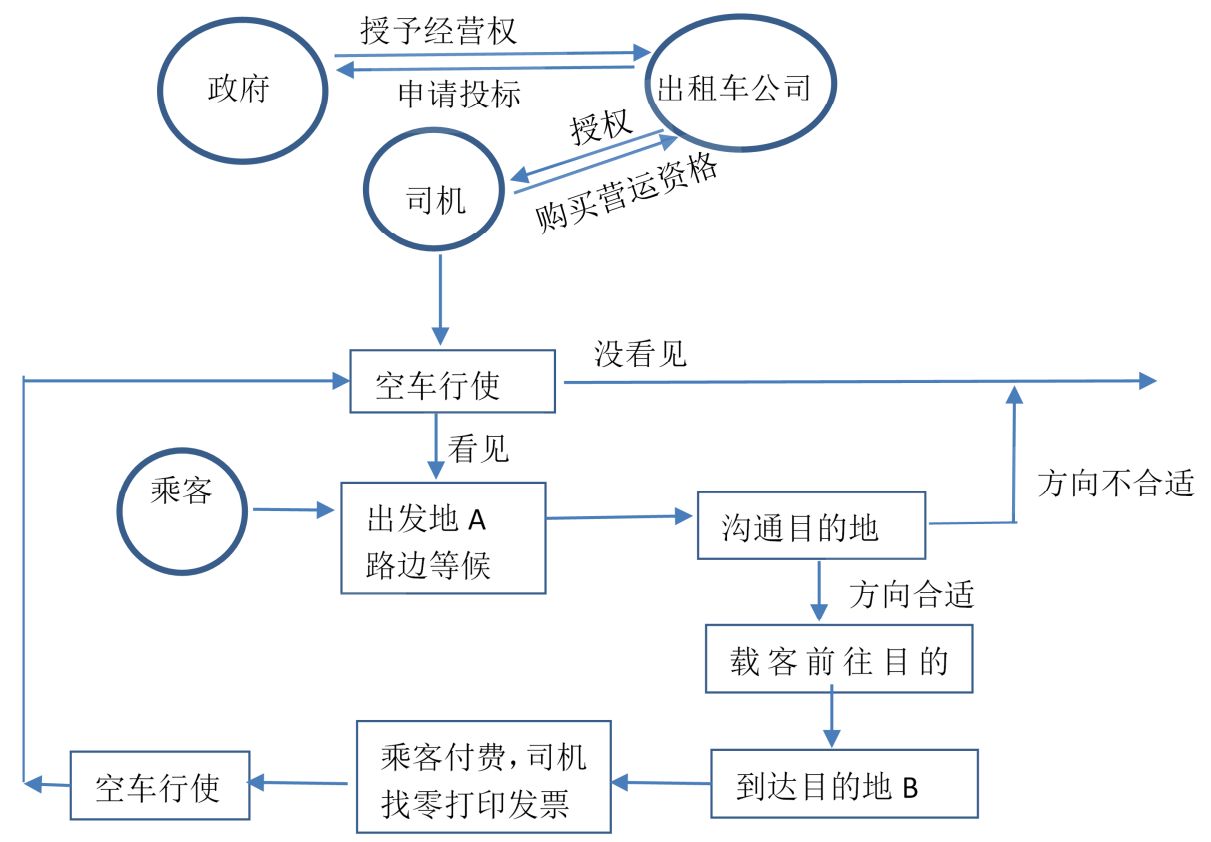

图7 传统出租车客运服务的活动流程图。 


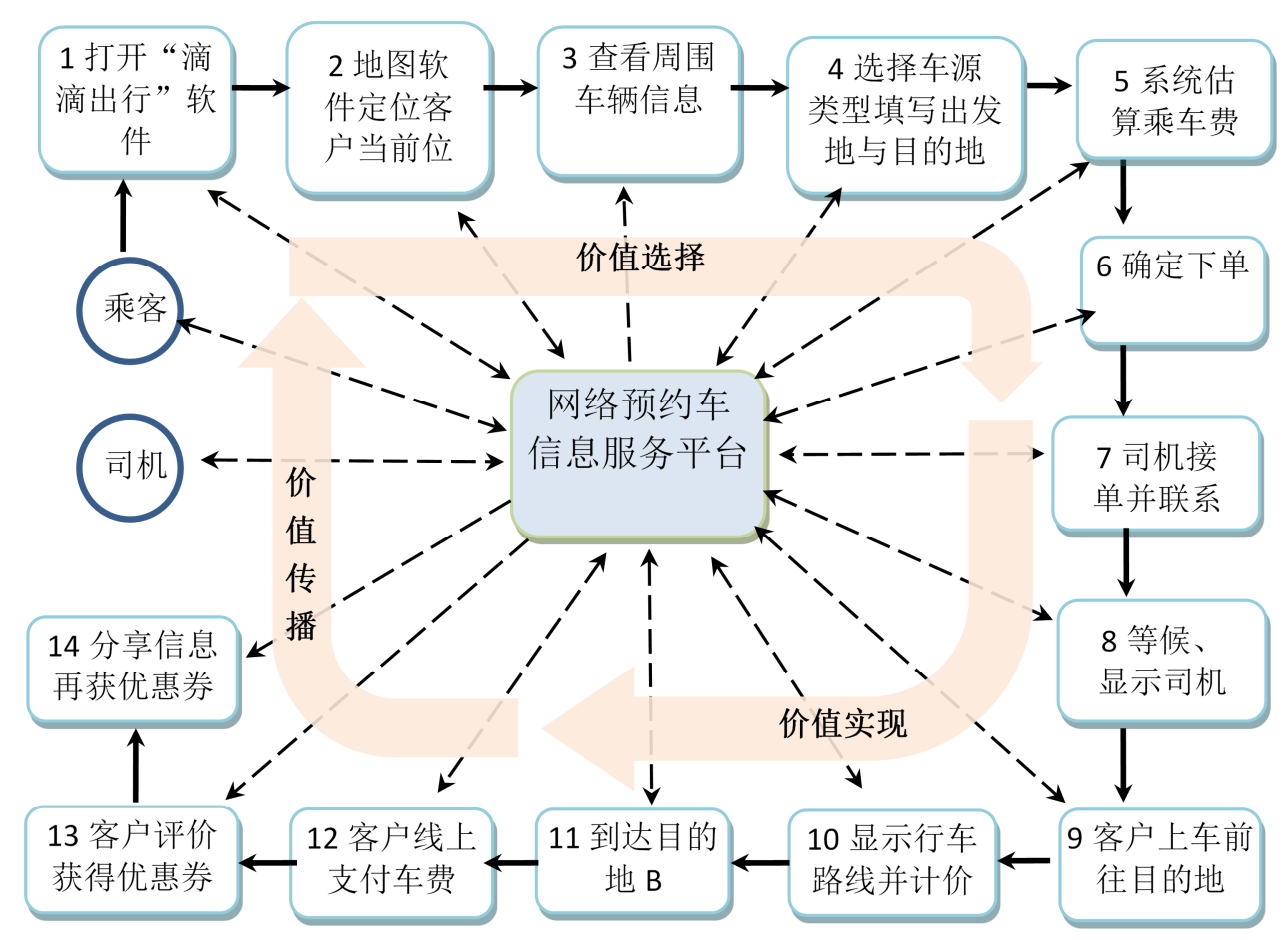

图8 网络预约出租车服务的活动流程。

与此同时, 作为服务供给的一方, 司机同样也面临信 息不对称的困扰。司机由于对顾客分布和需求信息了解不 充分, 使得其在与乘客接触时也往往带有一定的偶然性。 通常情况下, 司机不仅需要驾驶空车在街面上行驶, 同时 还要凭经验、凭肉眼观察和寻找路边有乘车需求的乘客。 低效率的空车行驶不但增加了司机的时间成本和燃油消 耗等，同时也增加了城市的污染排放。显而易见，在传统 出租车在城市出行服务过程中, 出租车的服务效能要比其 他公共交通工具要低很多, 其运行效能大约是常规公交的 三分之一。[19]从上述分析我们可看出, 随着经济的发展 和城市居民出行的个性化, 传统出租车行业的服务手段上 已不能有效适应当前城市居民出行的需求。

图8描绘了网络预约出租车服务的流程。在服务过程 中, 网络约车平台充当一个信息服务中介, 它利用大数据、 云计算、移动位置服务 (LBS) 和全球定位系统 (GPS) 等 现代信息技术手段对司机和乘客这些供需信息进行篮选、 整合和匹配，从而实现供需信息的有效对接。例如在网约 车 “滴滴出行” 服务过程中, 乘客首先会打开滴滴出行软 件查看当前位置的营运车辆的分布情况, 这时每种服务类 型的车辆在滴滴软件的地图界面中都可实时显示出来, 乘 客可以根据需要选择出行车辆种类, 如快车、专车、出租 车等。接着乘客需要输入出发地和目的地, 这时滴滴出行 信息服务平台会根据出发地和目的地估算出大概的费用 并显示在用户的屏幕中, 这个费用区分为拼车费用和不拼 车费用两种模式。用户可根据自己的出行需求进行相应的 选择。乘客一旦确定下单, 出行需求将形成订单通过移动 互联网传递到滴滴出行信息服务后台, 后台将自动向乘客 周围的司机个体发布订单信息。司机个体可根据自己所处 的位置和行车路线来决定是否接单。一旦接单成功, 滴滴
出行信息服务平台将会把司机的位置和个人资料（姓名、 车牌尾号、车辆颜色、所在位置) 实时显示在乘客的手机 界面当中。接下来, 司机需要通过电话联系乘客确认订单 和上车地点。当双方沟通确认无误后, 乘客将在协商的地 点等候司机, 这时手机软件一直保持实时显示司机当前行 使位置信息。司机到达指定地点接到乘客后, 司机即可开 启手机软件进入计费导航模式。与此同时, 乘客的手机上 将实时显示车辆行驶的路线以及计费信息。司机到达目的 地后, 司机将结束导航并停止计费, 这时滴滴出行信息服 务平台会向用户传送本次乘车的付费账单信息, 乘客在付 费界面可选择第三方支付（微信、支付宝等）完成付费。 付费完成后, 滴滴出行系统将请求乘客为此次司机服务打 分评价, 乘客评价完成后如果愿意将将滴滴出行服务链接 分享到社交网络将会获赠送出行赠券折扣等优惠, 这些优 惠可供乘客下次使用。

从营销价值链管理的角度来看, 图中活动 1 到活动 6 实际上是为乘客和司机提供了价值的选择, 活动 6 到活动 12 是完成价值创造的过程。活动 13 到活动 14 则是实现了价 值传播。在整个服务过程中, 起到关键作用的是非物质形 式的信息, 信息和信息技术增强了供给和需求的有效对接, 大大减少了打车出行过程中人们对物质和能源的消耗, 提 升出行服务的质量和效率。

\section{8. 结论}

经济的增长、产业结构的转型升级、社会的可持续发 展与自然生态环境之间的关系是相辅相成、辩证统一的。 人类社会过去两百多年来的工业经济曾过度地向大自然 索取, 这已给地球生态系统造成严重的伤害。如今, 中国 
推行的生态文明体制改革为人类社会的发展提供一个新 的发展方向, 它强调把人与自然看作是一个命运共同体, 努力运用新技术、新方法来实现人与自然的共同繁荣、共 同发展。当前信息经济的蓬勃发展是人类文明发展演变的 结果, 它将推动人类社会降低对物质和能源的消耗, 减少 对生态环境的破坏, 最大程度的实现人与自然的和谐发展。

\section{参考文献}

［1］丹尼斯. 梅多斯, 李涛、王智勇译, 增长的极限 [M], 工业 出版社2013，P70-P71

[2] 全球生态足迹网站, 各国生态足迹数据下载网址 [EB/OL]http://www. footprintnetwork. org/1icenses/pu blic-data-package-free-edition/

[3] 英格兰东安格利亚大学的“全球气候研究小组”网站 [EB/OL] http://www. cru. uea. ac. uk/news-events/-/asset_publi sher/XjiOuLnbgWRI/blog/new-global-temperature-visu alisations? inheritRedirect $=$ fal se\&redirect $=\mathrm{http} \% 3 \mathrm{~A} \%$ 2F\%2Fwww. cru. uea. ac. uk\%2Fnews-events\%3Fp_p_id\%3D10 1_INSTANCE_XjiOuLnbgWRI\%26p_p_lifecycle\%3D0\%26p_p_ state\%3Dnormal\%26p_p_mode\%3Dview\%26p_p_col_id\%3Dco lumn-1\%26p p col count\%3D1

[4]人民网, 美国宇航局预测2016将是历史上最热的一年 [EB/OL]

http://world. people. com. cn/n1/2016/0623/c1002-2847 3085. htm1

[5] 世界自然基金组织“2014生存星球报告” [R/OL]http://www. worldwildlife. org/pages/living-pl anet-report-2014/

[6] 刘东, 封志明, 杨艳昭, 基于生态足迹的中国生态承载力供 需平衡分析 $[\mathrm{J}]$ ，自然资源学报，2012第4期

[7] 世界银行网站，各国历年 GDP 数据统计 [EB/OL] http://data. worldbank. org. cn/indicator/NY. GDP. MKTP
.CD?order=wbapi_data_value_2014+wbapi_data_value+w bapi_data_value-last\&sort=desc

８］郑晓，产业结构与经济增长--中国战略性新兴产业发展问 题研究 [D]，中共中央党校，2012.04

[9] 美 国 商 务 部 经济分析局网站 [OL] http://www. bea. gov/industry/iedguide. htm\#gpo

[10］赵嘉, 唐家龙, 美国产业结构演进与现代产业体系发展及 其对中国的启示，科学学与科学技术管理 [J]2012年01月

[11] 贺京同, 素质提高、结构调整与产业升级-----基于中、美 两国三次产业的对比 $[J]$ 经济与管理研究，2016年第3期

[12] 丹尼斯. 梅多斯, 李涛、王智勇译, 增长的极限 [M], 工业 出版社，2013：165

[13] 杰里米. 里夫金, 第三次工业革命 $[\mathrm{M}]$, 张体伟, 孙豫宁译 中 信出版社，2012

[14] 林毅夫、董先安, 信息化、经济增长与社会转型 $[\mathrm{R} / \mathrm{OL}]$ 北 京大学国家发展研究院，2003 年 http://www. nsd. edu. cn/publications/tlg/2015/0627/2 0463. html

[15] 张作民, 信息产业对经济增长的影响与中国信息产业的发 展. 生产力研究 $[J] ， 2002,(5): 219-223$

[16] 中国信息通信研究院, 2015中国信息经济研究报告 [R/OL], 2015年9月 http://www. catr. cn/kxyj/qwfb/bps/201512/t20151211_ 2146702. html

[17] 张建华, 保罗. 罗默对新增长理论的贡献, 经济学动态 [J] 2004，第2期

[18］吴群琪，唐俊忠，出租客运的性质、地位及其应有的管理 模式 $[J] ，$ 城市问题，2011年第11期

[19] 陈燕申, 当前影响出租汽车行业稳定与发展的相关问题分 析 $[J] ，$ 城市管理，2009(2):116-122 